\title{
Paediatric Femoral Neck Fracture: Experience of Management of our Patients and a Review of the Literature
}

ISSN: 2576-8875

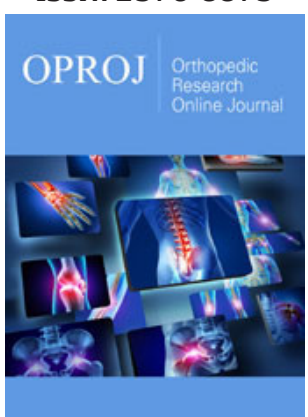

${ }^{* 1}$ Corresponding author: Emmanuel Owusu Ofori, Department of Surgery at Cape Coast Teaching Hospital, Ghana

Submission: 梅 March 19, 2019

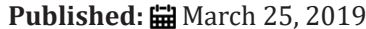

Volume 5 - Issue 3

How to cite this article: OFORI EO, DAYIE MSC-JK, BIN ALHASSAN BA, DOKU K, BAIDOO R. Paediatric Femoral Neck Fracture: Experience of Management of our Patients and a Review of the Literature. Ortho Res Online J. 5(3). OPROJ.000613.2019.

DOI: 10.31031/OPROJ.2019.05.000613

Copyright@ Emmanuel Owusu Ofori This article is distributed under the terms of the Creative Commons Attribution 4.0 International License, which permits unrestricted use and redistribution provided that the original author and source are credited.

\author{
Emmanuel Owusu Ofori ${ }^{1 *}$, Makafui SC-JK Dayie, Baba Alhaji Bin Alhassan", \\ Kingsley Doku² and Richard Baidoo ${ }^{2}$ \\ ${ }^{1}$ Department of Surgery, Cape Coast Teaching Hospital, Ghana
}

${ }^{2}$ Orthopaedic Surgery Unit, Department of Surgery, University of Cape Coast School of Medical Sciences and Cape Coast Teaching Hospital, Ghana

\begin{abstract}
Background: Femoral neck fractures are rare injuries in children, but their high incidence of long term complications make them an important clinical entity. The aim of this retrospective study was to analyze the clinical outcomes of paediatric femoral neck fractures that we managed over a 5-year period.

Methods: The study included 4 children ( 2 boys and 2 girls) who sustained femoral neck fractures and completed a minimum follow-up of two years. All The children had operative management either by open reduction and internal fixation (ORIF), or closed reduction and internal fixation (CRIF). The outcomes were analyzed using Ratliff criteria and record of complications was kept for all patients.

Results: The mean age of included patients was 11 years (range, 3 to 16 years). Based on Delbet's classification, there were no types I (transepiphyseal) and IV (intertrochanteric), 3 type II and 1 type III. A satisfactory outcome was obtained in all $4(100 \%)$ children even in a child who had cut out of the screws post-operative day 10 .

Conclusion: Despite a small series of internal fixation for paediatric hip fractures, we had encouraging outcomes with no avascular necrosis, no limb length discrepancy or non-union after a minimum followup of two years.
\end{abstract}

Keywords: Paediatric femoral neck fracture; Closed reduction; Open reduction; Internal fixation; Ratliff; Delbet classification

\section{Introduction}

Paediatric femoral neck fractures account for less than $1 \%$ of all paediatric fractures [1]. This low incidence of these fractures is attributed to the thick and strong periosteum cover of the bone of children [2]. Hence 80 to $90 \%$ of all femoral neck fractures in children are due to high-energy trauma such as falling from a height and road traffic accidents [2]. These fractures are however associated with high rate of complications such as coxa vara, delayed union and nonunion especially in patients treated conservatively as well as osteonecrosis, premature physeal closure and limb length discrepancy occurring more commonly patients with operative treatments. The high rate of complications is because the peculiar vascular and osseous anatomy of the paediatric proximal femur makes them vulnerable to injury. This fact was best summarized by Canale [3] stating that "hip fractures in children are of interest because of the frequency of complications rather than the frequency of fractures" [3]. We aimed to retrospectively review all cases of paediatric femoral neck fractures and analyze the treatment received and complications with the view of improving future outcomes.

\section{Method}

We retrospectively reviewed all children (less than 16 years old) with femoral neck fracture managed in the department of Surgery at the Cape Coast Teaching Hospital from January 2013 to December 2017. A total of 4 children ( 2 boys and 2 girls) who completed a minimum follow-up of at least 2 years were included in the study. The fractures were classified according to the Delbet classification which was popularized by Colonna [4]. The treatment 
modalities used were open reduction and internal fixation (ORIF) or closed reduction and internal fixation (CRIF) depending on the patient profile and the fracture pattern. Assessment of the final outcome was made at the last follow-up visit, 2 years after fixation was done using the Ratliff's criteria (Table 1); [1]. Radiographs were also evaluated for joint congruency, arthritic changes and avascular necrosis (AVN).

Table 1: Ratliff's criteria of clinical and radiographic assessment.

\begin{tabular}{|c|c|c|}
\hline & Good & Fair \\
\hline Pain & None or "ignore" & Occasional \\
\hline Movement & Full or terminal restriction & Greater than 50 percent \\
\hline Activity & Normal or avoids games & Normal or avoids games \\
\hline Radiographic indications & $\begin{array}{c}\text { Normal or some deformity of the } \\
\text { femoral neck }\end{array}$ & $\begin{array}{c}\text { Severe deformity of the femoral neck. } \\
\text { "Mild" avascular necrosis. }\end{array}$ \\
\hline
\end{tabular}

\section{Results}

The mean age of our patients was 11 years (range, 8 to 16 years) with 2 males and 2 females. The mechanisms of injury varied, with falling from height being the most common causative factor (2 patients). Road traffic accident (RTA) and injury sustained from school wall falling on thigh accounted for 1 case each. 3 cases $(75 \%)$ were of Delbet type II (transcervical) and 1 case (25\%) was of Delbet type III (cervicotrochanteric). There were no cases of Delbet type I (transepiphyseal separation) and Delbet type IV (intertrochanteric) in our study. The child involved in RTA as pedestrian had documented associated closed humeral neck fracture.
All the children had operative management either by open reduction and internal fixation (ORIF), or closed reduction and internal fixation (CRIF) under fluoroscopy since all 4 patients had displaced fractures. After patient were followed up for at least 2 years, all 4 were found to be asymptomatic clinically with no pain, no limp shortening and had no radiological evidence of AVN. Hence using the Ratliff's criteria, all 4 patients had good outcomes (100\%) as shown in Table 2, despite 1 patient having complication of primary screw cut out on postoperative day 10 with subsequent radiograph showing implant failure (Figure 1).

Table 2: Summary results.

\begin{tabular}{|c|c|c|c|c|c|c|c|}
\hline Patient & Gender & Age & Mechanism & Delbet & Type of fixation & Complications & Ratliff \\
\hline & & (years) & of injury & classification & & & outcome \\
\hline 1 & Male & 8 & $\begin{array}{c}\text { School wall fell on right } \\
\text { thigh }\end{array}$ & III & $\begin{array}{c}\text { CLOSED REDUCTION (CR) } \\
\text { +PERCUTANEOUS PINNING } \\
\text { WITH } 2 \text { CANNULATED } \\
\text { SCREWS (PP) }\end{array}$ & $\begin{array}{l}\text { REFRACTURE POST } \\
\text { OP DAY } 10 \text { Re-oper- } \\
\text { ated (CR }+22 \mathrm{~mm} \\
\text { Kirschner Wire + } \\
\text { No. } 5 \text { TiCron Tension } \\
\text { band + Hip Spica) }\end{array}$ & Good \\
\hline 2 & Female & 9 & RTA & II & $\mathrm{CR}+\mathrm{PP}$ & - & Good \\
\hline 3 & Female & 11 & Fell from a height & II & $\mathrm{CR}+\mathrm{PP}$ & - & Good \\
\hline 4 & Male & 16 & Fell from a height & II & $\begin{array}{l}\text { ORIF WITH } 2 \text { CANNULAT- } \\
\text { ED SCREWS }\end{array}$ & - & Good \\
\hline
\end{tabular}

ORIF: Open Reduction and Internal Fixation, CR: Closed Reduction, PP: Percutaneous Pinning 


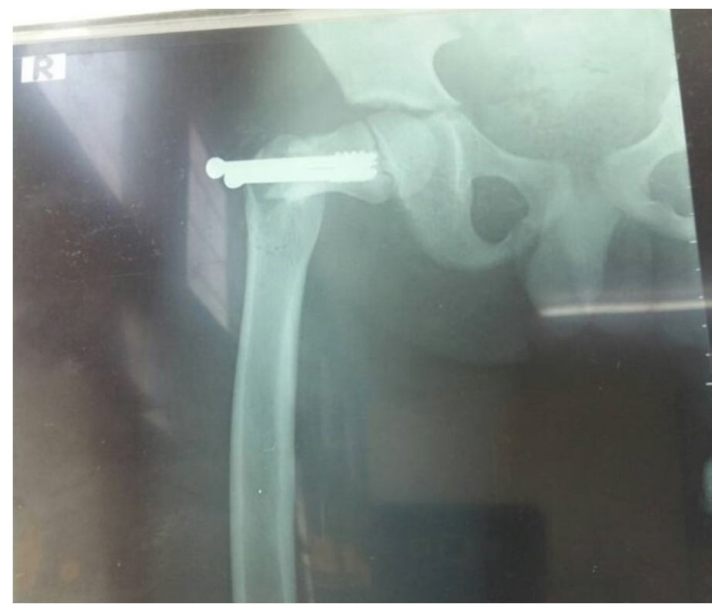

Figure 1: X-ray showing failed percutaneous pinning with two cannulated screws post op day 10.

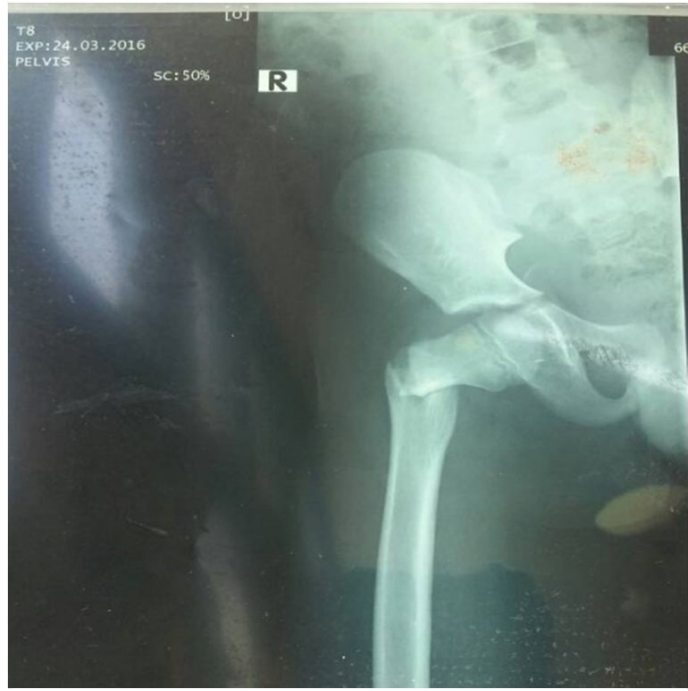

Figure 2: X-ray showing displaced cervicotrochanteric fracture of the right femur.

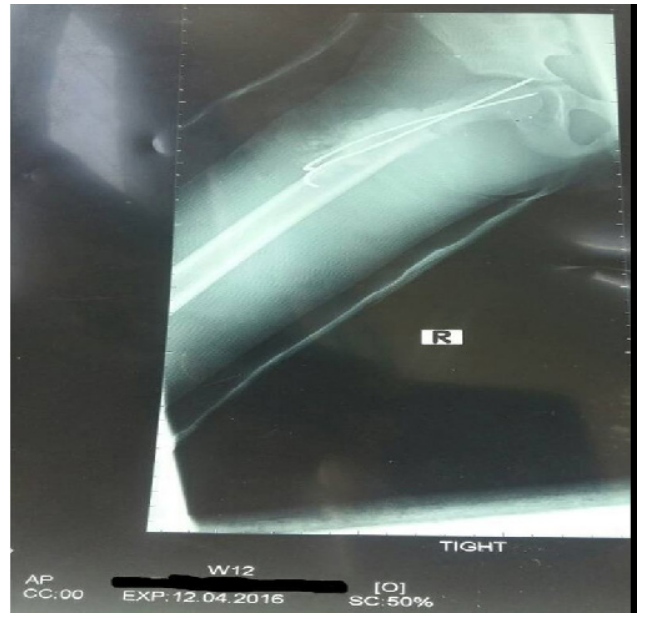

Figure 3: Post re-op $\mathrm{x}$-ray showing two $2 \mathrm{~mm}$ kirschner wires and hip spica.
This occurred in the 8-year-old boy who had his falling school wall landing on the right thigh whilst playing at school (Figure 2). He had closed reduction and percutaneous pinning with 2 cannulated screws without hip spica. Child was doing well post operatively on the ward until day 10 when he suddenly sat upright in a chair to receive lessons from the school teacher. He was in sudden excruciating pain and subsequent repeated radiograph confirmed the cut out of the cannulated screws (Figure 1). He later had closed reduction and percutaneous pinning with two $2 \mathrm{~mm}$-Kirschner wire and No. 5 TiCron tension band as well as hip spica applied after previous screws removed (Figure $3 \& 4$ ).

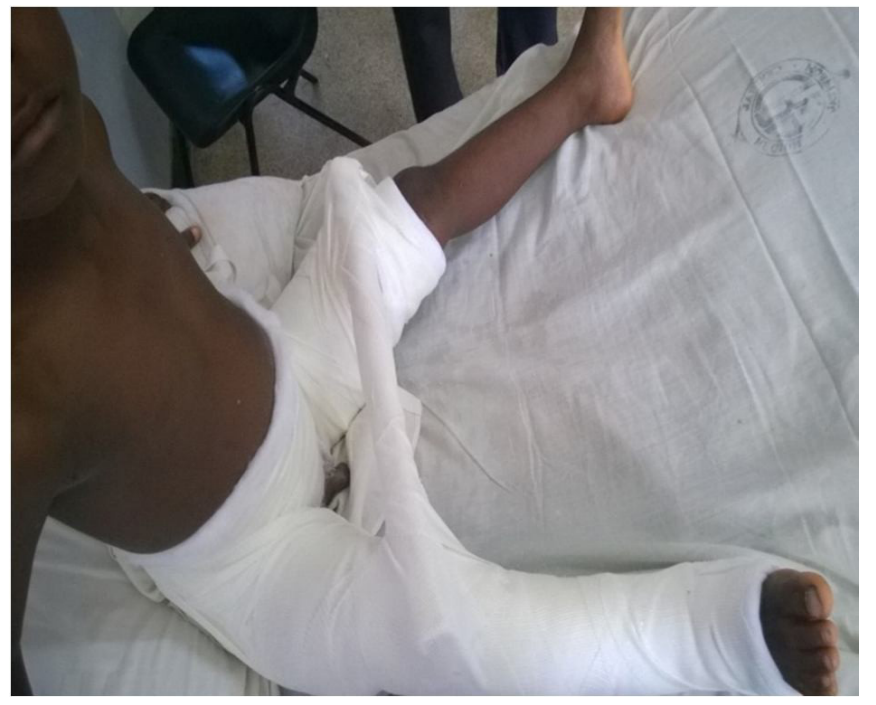

Figure 4: child sitting comfortably in bed with a hip spica post re-op.

\section{Discussion}

The peculiar anatomy of the femoral neck of children makes most of their injuries sustained usually as a result of high energy trauma. Hence these fractures are associated with other concomitant injuries which should also be addressed. Most studies found high incidence of fractures due to RTA and followed by falling from height which concurs with the rising vehicular accidents globally. Conversely, our study had incidence of $50 \%$ for falling from height and $25 \%$ for RTA which is inconsistent with the incidence rates in other literatures $[1,5]$. This difference could be due to the relatively small number of patients included in the study. Delbet type II was the most common fracture pattern with incidence of 3 patients $(75 \%)$ being consistent with existing incidence in the literature $[1,6,7]$. The child who had the RTA also had associated closed humeral neck (surgical) fracture as stated earlier and had closed reduction and intramedullary Kirschner wiring done in addition to fixation of the femoral neck fracture.

With the choice of operative treatment many different procedures have been described including close/open reduction and internal fixation using K-wires, cannulated screws, fibula or nails [4]. There is no evidence in the literature that one or other implant influences the rate of postoperative complications such as avascular femoral head necrosis or coxa vara [8]. In addition, 
controversy exists in the literature whether to perform open or closed reduction. Many reports advocate open reduction to ensure proper excision of the pseudo-arthrosis, freshening of the fracture, anatomic reduction and to avoid damaging intracapsular vessels [9]. Canale [3] reported a decrease in complications in all, undisplaced or displaced, type II fractures, after reduction and internal fixation by pins or screws [4]. Heiser [10] also stated that if it is necessary to bridge the physis then it is preferable to do so with smooth K-wires to prevent premature closure of the physis [10].

Damany et al. [11] in a meta-analysis of 18 articles on fracture neck femur of 564 patients, showed an overall nonunion rate of $8.9 \%$. They found that with open reduction the rate of nonunion increased to $11.2 \%$ compared with $4.7 \%$ for fractures treated with closed reduction hence our choice of closed reduction for 3 out of 4 of the cases reported [11]. Sharma et al. [8] also advocates for the use of the minimally invasive method of intertrochanteric valgus osteotomy and internal fixation stabilized using Kirschner wire and screws which is technically simple yet effective method of treating difficult fracture neck femur as was used in her case report [8].

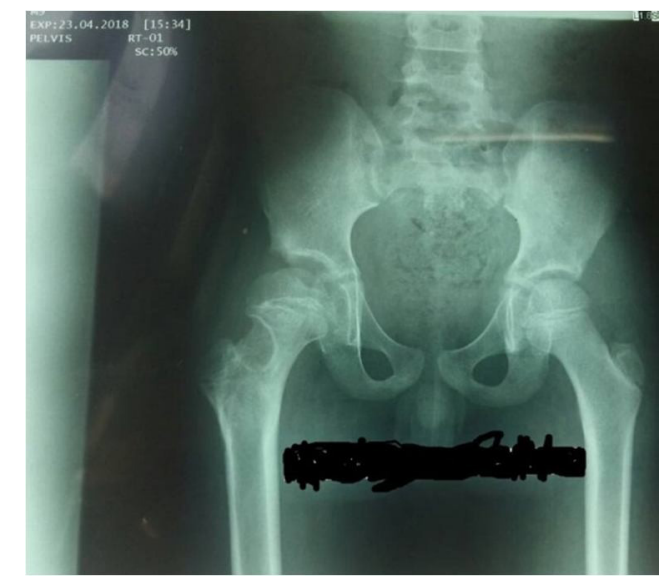

Figure 5: 2 years follow up x-ray with good Ratliff outcome.

In our case that had complication of cut out of the screws on postoperative day 10, from hindsight, child should have been placed in hip spica. In addition, the close proximity of the screws could have contributed to the cut out experienced. On the approach to refixing a failed internal fixation of paediatric femoral neck fracture as described in most of the series studied, $[1,6,7]$ could not be applied to our case hence the adoption of $22 \mathrm{~mm}$-Kirschner wires with tension band using strong No.5 TiCron nonabsorbable suture and hip spica this time applied. Our choice was based on it being economical, less bulky implant, still minimally invasive and probably exerting more compression at the fracture site. Hence achieving a good outcome based on the Ratliff criteria as shown in Figure 5.

The complications such as avascular necrosis, limb length discrepancy and non-union were not observed in our study. This good outcome may be due to many factors: proper fracture reduction; secure fixation by spica; and the absence of any preoperative AVN. Though this is a small case series, the outcome is satisfactory.

\section{Conclusion}

Despite a small series of internal fixation for paediatric hip fractures, we had encouraging outcomes with no avascular necrosis, no limb length discrepancy or non-union after a minimum followup of two years.

\section{References}

1. Ratliff AH (1962) Fractures of the neck of the femur in children. J Bone Joint Surg Br 44(3): 528-542.

2. Meyers MH (1985) Fractures of the hip. Year Book Medical Publishers, Chicago, USA.

3. Canale ST, Bourland WL (1977) Fracture of the neck and intertrochanteric region of the femur in children. J Bone Joint Surg Am 59(4): 431-443.

4. Colonna PC (1929) Fracture of the neck of the femur in children. Am J Surg 6(6): 793-797.

5. Cheng JC, Tang N (1999) Decompression and stable internal fixation of femoral neck fractures in children can affect the outcome. J Pediatr Orthop 19(3): 338-343.

6. Kamal B, Pebam S, Sandeep P, Vishal K, Uttam S, et al. (2011) Pediatric femoral neck fractures: our 10 years of experience. Clinics in Orthopedic Surgery3: 302-308.

7. Quick (2005) Pediatric fractures and dislocations of the hip and pelvis. Clin Orthop Relat Res (432): 87-96.

8. Amit S, Anurag T, Tarun V, Lalit M (2016) Non-union fracture neck femur in a toddler: Reconstructed by valgus osteotomy-A minimally invasive approach. Journal of Clinical Orthopaedics and Trauma 7S (2016): 8-11.

9. Song KS (2010) Displaced fracture of the femoral neck in children: open versus closed reduction. J Bone Joint Surg 92(8): 1148-1151.

10. Heiser JM, Opphenheim WL (1980) Fracture of the hip in children: a review of 40 cases. Clin Orthop 12: 355-358.

11. Damany DS, Parker MJ, Chojnowski A (2005) Complications after intracapsular hip fractures in young adults. A meta-analysis of 18 published studies involving 564 fractures. Injury 36: 131-141. 